\title{
Annotation
}

\section{Dimensional Correspondences Between Deciduous and Permanent Teeth}

\author{
Stanley M. Garn, Patricta E. Cole, and Robert L. Wainright \\ Center for Human Growth and Development, and Department of Anthropology, University \\ of Michigan, Ann Arbor, Michigan 48109, USA
}

\section{J Dent Res 56(10):1214 October 1977 .}

Although dimensional correspondence between individual deciduous teeth and their permanent successors have been explored for the "prediction" of permanent tooth sizes (HrXoN and OLDFATHER, Angle Orthodont 28:236, 1958) information derived from single-source data is still limited and to the mesiodistal dimension (Lyselx, Sartryck ur Odontologisk Tidskrift 65:571, 1957; Lysell, Acta Odontol Scand 18: 1, 1960; Moorrees and Reed, Arch Oral Biol $9: 685,1964)$. Accordingly, we have explored dimensional correspondences between deciduous teeth and their successors in 208 boys and girls from the University of Michigan Growth Study making use of both mesiodistal and buccolingual crown diameters as derived from casts using optical-scanner (OPTOCOM) coordinates (VAN Der Linden et al, $J$ Dent Res 51:1100, 1972).

Initial comparison of the paired tooth dimensions, taking boys and girls separately, showed no sex differences in the magnitude or trend of correlations. Accordingly, the sex-specific data were pooled to maximize sample size. When this was done, correlations between individual deciduous teeth and their permanent successors ranged from 0.23 to 0.61 for the mesiodistal diameters and 0.11 to 0.44 for the buccolingual diameters (Table). Overall, pooled correlations for the mesiodistal diameters $(r=$ $0.41)$ were slightly higher than corresponding pooled correlations for the buccolingual diameters ( $r=0.32$ ), a difference that may be viewed as marginally significant. In general, the highest and lowest correlations for the mesiodistal and buccolingual diameters involved the same pairs of teeth, as summarized by a 0.69 rank-order correlation ( $\mathrm{RHO})$.

This study was supported in part by Grant No. DE03610 from the National Institutes of Health.

Received for publication March 17, 1977.

Accepted for publication May 31, 1977.
TABLE

Dimensional Corkespondences Between Deciduous and Permanent Teeth

\begin{tabular}{|c|c|c|c|c|}
\hline \multirow{2}{*}{$\begin{array}{c}\text { Teeth } \\
\text { Compared }\end{array}$} & \multicolumn{2}{|c|}{ Mesiodistal dia } & \multicolumn{2}{|c|}{ Buccolingual dia } \\
\hline & $N^{1}$ & $r$ & $\mathbf{N}^{1}$ & $\mathbf{r}$ \\
\hline \multicolumn{5}{|c|}{ Maxilla } \\
\hline $\mathrm{I}^{1} \mathrm{I}^{1}$ & 160 & 0.50 & 158 & 0.42 \\
\hline $\mathrm{I}^{2} \mathrm{I}^{2}$ & .60 & 0.23 & 158 & 0.27 \\
\hline $\mathrm{c} C$ & 133 & 0.25 & 133 & 0.11 \\
\hline$d m^{1} p^{1}$ & 137 & 0.61 & 137 & 0.44 \\
\hline $\mathrm{dm}^{2} \mathrm{P}^{2}$ & 111 & 0.43 & 111 & 0.34 \\
\hline \multicolumn{5}{|c|}{ Mandible } \\
\hline$i_{1} I_{1}$ & 139 & 0.49 & 136 & 0.18 \\
\hline$\vec{i}_{2} \bar{I}_{2}$ & 167 & 0.47 & 166 & 0.27 \\
\hline $\mathrm{c} C$ & 154 & 0.28 & 154 & 0.27 \\
\hline $\mathbf{d m}_{1} P_{1}$ & 141 & 0.32 & 140 & 0.39 \\
\hline $\mathrm{dm}_{2} \mathrm{P}_{2}^{1}$ & 116 & 0.51 & 116 & 0.44 \\
\hline mean $r$ & & $0.41^{2}$ & & $0.32^{2}$ \\
\hline
\end{tabular}

${ }^{I}$ No. of individuals.

${ }^{2}$ Rank order correlation between mesiodistal and buccolingual correlations equals 0.73 .

With deciduous versus permanent crownsize correlations of the magnitudes shown, close "prediction" of permanent tooth diameters from deciduous predecessors is manifestly impractical. Even the highest multiple correlations involving estimation of $\mathrm{P} 1$ using $\mathrm{dc}, \mathrm{dml}$, and $\mathrm{dm} 2$ were no higher than 0.63 . Nevertheless, it is impressive that dimensions of deciduous tooth crowns should show correspondences as high as 0.5 to 0.6 with the crowns of permanent teeth, even though the former may be completely developed not much later than the 7 th month of gestation while the latter form as late as the $3 \mathrm{rd}$ and 4 th years of life (cf GARN, LEwIS, and Polacheck, J Dent Res $38: 135,1959)$. Clearly, common control mechanisms operating from prenatal time through the pre-school years are responsible for these deciduous-permanent crown size correspondences involving both conventional dimensions. 